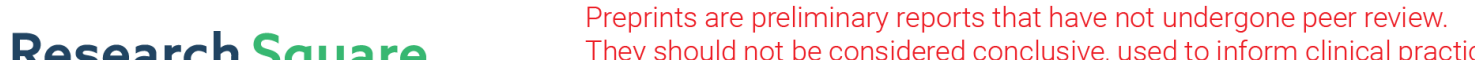 They should not be considered conclusive, used to inform clinical practice, or referenced by the media as validated information. \\ Thermodynamic Performance Study on the Novel Efficient Flow Pattern Global Construction Evaporator
}

\section{Tianming Zhong ( $D$ 125482766@qq.com )}

Zhongkai University of Agriculture and Engineering Haoxian Bai

Zhongkai University of Agriculture and Engineering

\section{LIxing Ding}

Zhongkai University of Agriculture and Engineering

\section{Yu Xie}

Zhongkai University of Agriculture and Engineering

\section{Shu Chen}

Zhongkai University of Agriculture and Engineering

\section{Yuhe Luo}

Zhongkai University of Agriculture and Engineering

\section{Guang Zhou}

Zhongkai University of Agriculture and Engineering

\section{Research Article}

Keywords: heat transfer enhancement, full nucleate boiling, numerical analysis, thermodynamic performance, efficient flow pattern global construction evaporator

Posted Date: June 14th, 2021

DOI: https://doi.org/10.21203/rs.3.rs-620448/v1

License: (c) (1) This work is licensed under a Creative Commons Attribution 4.0 International License. Read Full License 


\title{
Thermodynamic Performance Study on the Novel Efficient Flow Pattern \\ Global Construction Evaporator
}

\begin{abstract}
To improve in-tube evaporation heat transfer at low quality, a novel evaporator based on efficient flow pattern global construction heat transfer enhancement mechanism is built, called the efficient flow pattern global construction evaporator (EFGE). The numerical analysis and experimental study of the thermodynamic performance of the EFGE are performed. Results show that the evaporation heat transfer coefficient (HTC) of the EFGE is $0.34-1.04$ times that of a common parallel flow evaporator (PFE) and the pressure drop of the EFGE is only $80 \%-116 \%$ of that of a common PFE at quality 0.9 . The theoretical nonuniformity of the evaporation HTC between low- and high-quality flow is approximately $12 \%-67 \%$, which $55 \%-72 \%$ of the pressure drop. The numerical analysis results are in good agreement with the finding that the EFGE has better thermodynamic performance than the PFE in terms of friction power reduction and minimum entropy generation number.
\end{abstract}

Keywords heat transfer enhancement, full nucleate boiling, numerical analysis, thermodynamic performance, efficient flow pattern global construction evaporator

\section{NONMENCLATURE}

\section{Abbreviation}

\begin{tabular}{|llll|}
\hline EFGE & Efficient flow pattern global construction & NS & Minimum entropy generation number \\
& evaporator & PFE & Parallel flow evaporator \\
FPR & Friction power ratio & & \\
HTC & Heat transfer coefficient & & \\
\hline
\end{tabular}

\section{Symbols}

\begin{tabular}{|llll|}
\hline$A$ & Heat transfer area $\left(\mathrm{m}^{2}\right)$ & $P^{\prime \prime}$ & Friction power $(\mathrm{W})$ \\
$\mathrm{C}_{\mathrm{c}}$ & Contraction coefficient & $p$ & Pressure drop $(\mathrm{kPa})$ \\
$c_{\mathrm{p}}$ & Specific heat capacity $\left(\mathrm{Jkg}^{-1} \mathrm{~K}^{-1}\right)$ & $\triangle P$ & Pressure difference $(\mathrm{kPa})$ \\
$d$ & Diameter of tube $(\mathrm{mm})$ & $Q_{\mathrm{e}}$ & Heat load $(\mathrm{J})$ \\
\hline
\end{tabular}




\begin{tabular}{|llll|}
\hline$F$ & Convective enhancement factor & $S$ & Entropy $\left(\mathrm{WK}^{-1}\right)$ \\
$\mathrm{Fr}_{\mathrm{m}}$ & Froude number & $\mathrm{Su}$ & Nucleate boiling suppression factor \\
$f$ & Friction factor & $T$ & Thermodynamic temperature $(\mathrm{K})$ \\
$G$ & Mass flux $\left(\mathrm{kgm}^{-2} \mathrm{~s}^{-1}\right)$ & $V$ & Volume flow rate $\left(\mathrm{m}^{3} \mathrm{~s}^{-1}\right)$ \\
$h$ & Heat transfer coefficient $\left(\mathrm{Wm}^{-2} \mathrm{~K}^{-1}\right)$ & $X$ & Lockhart-Martinelli parameter \\
$h_{c}$ & Convective effects & $x$ & Vapor quality \\
$I_{\mathrm{lv}}$ & Specific enthalpy $\left(\mathrm{Jkg}^{-1}\right)$ & $\alpha$ & Void fraction \\
$K$ & Thermal conductivity $\left(\mathrm{Wm}^{-1} \mathrm{k}^{-1}\right)$ & $\rho$ & Density $\left(\mathrm{kgm}^{-3}\right)$ \\
$L$ & Total tube length $(\mathrm{m})$ & $\mu$ & Dynamic viscosity $\left(\mathrm{Nsm}^{-2}\right)$ \\
$m$ & Mass flow rate $\left(\mathrm{kgs}^{-1}\right)$ & $\sigma$ & Surface tension $\left(\mathrm{Nm}^{-1}\right)$ \\
$N$ & Tube number & & \\
\hline
\end{tabular}

\section{Subscripts}

\begin{tabular}{|llll|}
\hline$a ; r$ & Air; Refrigerant & sat & Saturate \\
$H F ; L F$ & High quality flow; low quality flow & $t p$ & Two phase \\
$i$ & In-tube & $v ; l$ & Vapor; Liquid \\
in $;$ out & Inlet; outlet & $w$ & Tube wall \\
$m$ & Average & & \\
\hline
\end{tabular}

\section{INTRODUCTION}

Evaporator selection is a critical factor for refrigeration system efficiency. Some studies have been conducted to search high-efficiency evaporators and explore their thermodynamic performance. In fact, a large pressure drop indicates high-efficiency heat transfer. Thus, how to improve heat transfer and reduce pressure drop on evaporators are key aspects. Some researchers studied the effect of evaporator structure on evaporation heat transfer improvement ${ }^{[1,2]}$. Jo et al. ${ }^{[3]}$ investigated evaporation heat transfer characteristics in a novel shell-and-plate heat exchanger and indicated that the heat transfer coefficient of the novel shell-and-plate heat exchanger is $19 \%$ higher than that of the plate heat exchanger and the pressure drop of the former is $7.6 \%$ lower than that of the latter. Bustamante et al. ${ }^{[4]}$ experimentally studied the thermodynamic performance of different 
rectangular tubes at film Reynolds numbers of 48-544; they found that heat transfer coefficient obviously improves when the ratio between width and height increases and film breakdown occurs. Li et al. ${ }^{[5]}$ used R134a to study the heat transfer performance of an evaporator without inlet restriction and another with inlet restriction The results show that the cooling capacities of the evaporator with inlet restriction is $4.1 \%-13.3 \%$ less than those of the evaporator without inlet restriction.

Some studies on the heat transfer and resistance characteristic of evaporators have been conducted in recent years ${ }^{[6-8]}$. Song et al. ${ }^{[9]}$ investigated the evaporation heat transfer and pressure drop of R-245fa in a shell and plate heat exchanger. The study shows that evaporation heat transfer forms a peak area when the quality is approximately $0.6-0.9$ and presents a new heat transfer correlation with prediction of $\pm 20 \%$, but pressure drop increases nearly linearly. Shafaee et al. ${ }^{[10]}$ studied the heat transfer characteristics of corrugated tubes with R-600a at a high evaporating temperature $(331 \mathrm{~K})$; they found that the heat transfer coefficient at quality of 0.7 is 1.6 times that at a quality of 0.6 , but the heat transfer coefficient at quality of 0.6 is only 1.2 times that at quality of 0.1 . Tang et al. ${ }^{[11]}$ experimentally investigated nuclear boiling heat transfer characteristics in novel inter-micro-finned tube with water; the results indicate that high-efficiency heat transfer occurs during full nuclear boiling, but heat transfer deteriorates rapidly when water undergoes transition boiling.

Zhong et al. ${ }^{[12]}$ presented a novel efficient flow pattern global construction evaporator. The EFGE adopts short tubes in a parallel arrangement and drains gas and some liquid with a quality distributor to form high-quality flow during the evaporation process. The EFGE maintains high evaporation heat transfer efficiency in the whole passes. Zhong et al. ${ }^{[13]}$ take a preliminary study on heat transfer mechanism and the structure of the EFGE. Currently, the numerical analysis and experimental study of the EFGE have not been conducted and are thus the foci of this work.

\section{Novel efficient flow pattern global construction evaporator}

\subsection{Novel heat transfer enhancement mechanism}

Based on the classical theory of Nakiyama, boiling heat transfer coefficient (HTC) increases slowly before full nuclear boiling, but boiling HTC increases rapidly during full nuclear boiling up to film boiling because bubbles detach from tube walls and this condition leads to strong destabilization ${ }^{[14]}$. The high-efficiency heat transfer area of boiling in a tube is the high-quality area of approximately $0.70-0.95$. In an original flow at a quality 0.3 , the original flow is separated to a flow with a high quality of approximately 0.8 and a flow with a low quality of approximately 0.09 , as shown in Fig.1. The HTC of a flow with low quality only decreases slightly, whereas that of a flow with high quality increases rapidly. Overall, the boiling HTC of an original low-quality flow can be improved obviously. This novel heat transfer enhancement mechanism is called efficient flow pattern global construction heat transfer enhancement mechanism. 


\subsection{Structure of novel evaporator}

Fig.2 is the EFGE based on the efficient flow pattern global construction heat transfer enhancement mechanism. The EFGE consists of finned tubes and a pair of headers, and the tubes connect to the headers. The header is set with a baffle group in the header at the junction of the front and rear tube, 10 baffle groups are arranged on both headers. The evaporators are divided into 11 passes and the baffle groups in 1-9 passes are composed of a perforated baffle with conduits and a blind baffle, while the baffle groups in 10-11 passes only include blind baffles (no perforated baffle is needed at high quality). The baffle with conduits is called the quality distributor, the diameter of the conduit ranges from $3 \mathrm{~mm}$ to $5 \mathrm{~mm}$, and the length of the conduit ranges from $5 \mathrm{~mm}$ to $25 \mathrm{~mm}$. The the quality distributor is set in front of the blind baffle along with the flow, some tubes are arranged between both baffles. The tubes are inserted into both headers, and the inlet of the evaporator is set at the bottom. The working principle of the header with quality distributors is as follows: After a two-phase refrigerant with low quality enters the header, the liquid and vapor flow upward along the header tube, then meets the quality distributor. Given that the density of the liquid is much higher than that of the vapor, some liquids cover the baffle surface of the quality distributor, and vapor and droplets mostly appear in the space under the liquid layer. The liquid layer covering the baffle surface can't pass the conduits of quality distributor easily. As a result, vapor and some liquids will pass the quality distributor, enter the space between the blind baffle and quality distributor, form a high-quality flow with a quality of approximately $0.70-0.95$, and generate a high-efficiency boiling area. Most liquids will enter the heat transfer tubes before the quality distributor because of large gravity and secondary circulation, forming a low-quality flow that is close to full saturation. The passes take the same process until the quality of flow reaches $0.70-0.95$. That is, the passes with quality of $0.70-0.95$ are not set quality distributors. When high-efficiency boiling areas are formed in all the tube passes, the heat transfer of the EFGE will be improved significantly. Notably, the quality distributor used in the EFGE cannot distribute the flow quality accurately, and thus test results may deviate from the theoretical suitable quality area (quality of $0.70-0.95$ ). Then, the thermodynamic performance of the EFGE with 22 tubes and two tubes per pass is experimental studied. As a comparison, a parallel flow evaporator (PFE) with 22 tubes and 11 tube passes is studied. There is no accurate theoretical calculation method for perforation and conduit structure of the baffles, the best one from three experiential designed samples is selected in the experiment. A PFE has no quality distributor in both headers, that is, the EFGE will become the PFE when all the quality distributors are removed directly. Table 1 shows the sizes of both evaporators. Fig.3 presents the block diagram of the EFGE and indicates the details in the experiment.

\section{Theoretical method}

\subsection{Correlation}

A classical correlation presented by Kanizawa is employed for the analysis of the effect of efficient flow pattern 
global construction heat transfer enhancement mechanism on the EFGE ${ }^{[15]}$. The correlation is verified that predicts HTC accurately ${ }^{[16]}$. The form is as follows:

$$
\begin{gathered}
h=F h_{c}+S h_{n b} \\
h_{n b}=0.0546 \times \frac{k_{l}}{d_{b}}\left[\left(\frac{\rho_{v}}{\rho_{l}}\right)^{0.5}\left(\frac{\Phi d_{b}}{k_{l} T_{s a t}}\right)\right]^{0.67}\left(\frac{\rho_{l}-\rho_{v}}{\rho_{l}}\right)^{-4.33}\left(I_{l v} d_{b}^{2}\left(\frac{\rho_{l} c_{p l}}{k_{l}}\right)^{2}\right)^{0.248}
\end{gathered}
$$

where $k$ is thermal conductivity, $\phi$ is the heat flux, $T_{\text {sat }}$ is the saturation temperature (in Kelvin), $\rho$ is the fluid density, $\mu$ is the dynamic viscosity, $c_{p}$ is the specific heat at constant pressure, $I_{l v}$ is the vaporization enthalpy, and $d_{b}$ is the bubble equilibrium break-off diameter, which is calculated by

$$
d_{b}=0.51 \sqrt{2 \sigma /\left[g\left(\rho_{l}-\rho_{v}\right)\right]}
$$

where $\sigma$ is the surface tension. The HTC related to the convective effect $h_{c}$ is

$$
h_{c}=0.023 \times \frac{k_{l}}{d} \operatorname{Re}_{l}^{0.8} \operatorname{Pr}_{l}^{1 / 3}
$$

where $d$ is the tube diameter, $\operatorname{Re}_{l}$ is the liquid Reynolds number, and $\operatorname{Pr}_{l}$ is the liquid Prandtl number. The liquid Reynolds number is given as

$$
\operatorname{Re}_{l}=\frac{G(1-x) d}{\mu_{l}}
$$

The convective enhancement factor $F$ and nucleate boiling suppression factor $S u$ are calculated by

$$
\begin{gathered}
F=1+\frac{2.50 X^{-1.32}}{1+W e^{0.24}} \\
S u=\frac{1.06 B d^{-8.10^{-3}}}{1+0.12\left(\operatorname{Re}_{\mathrm{tp}} / 10000\right)^{0.86}}
\end{gathered}
$$

The Weber number and the gas velocity are given as

$$
\begin{gathered}
W e=\frac{\rho_{v} u_{v}^{2} d}{\sigma} \\
u_{v}=\frac{G x}{\rho_{v} \alpha}
\end{gathered}
$$

The void fraction $\alpha$ is 


$$
\alpha=\left[1+1.021 \times \operatorname{Fr}_{m}^{-0.092}\left(\frac{\mu_{l}}{\mu_{v}}\right)^{-0.368}\left(\frac{\rho_{v}}{\rho_{l}}\right)^{1 / 3}\left(\frac{1-x}{x}\right)^{2 / 3}\right]^{-1}
$$

The Froude number $F r_{m}$ is

$$
\begin{gathered}
F r_{m}=\frac{G^{2}}{\left(\rho_{l}-\rho_{v}\right)^{2} g d} \\
X=\left\{\begin{array}{l}
X_{t t}=\left(\frac{1-x}{x}\right)^{0.9}\left(\frac{\rho_{v}}{\rho_{l}}\right)^{0.5}\left(\frac{\mu_{l}}{\mu_{v}}\right)^{0.1} \text { for } \operatorname{Re}_{v}>1000 \\
X_{t t}=\frac{1}{18.7} \operatorname{Re}_{v}^{0.4}\left(\frac{1-x}{x}\right)^{0.9}\left(\frac{\rho_{v}}{\rho_{l}}\right)^{0.5}\left(\frac{\mu_{l}}{\mu_{v}}\right)^{0.1} \text { for } \operatorname{Re}_{v} \leq 1000
\end{array}\right.
\end{gathered}
$$

The Lockhart-Martinelli parameter $X$ is given as

The two-phase Reynolds number and the Bond number are given respectively as

$$
\begin{gathered}
\mathrm{Re}_{\mathrm{tp}}=\operatorname{Re}_{l o} F^{1.25} \\
B d=\frac{\left(\rho_{l}-\rho_{\nu}\right) d^{2} g}{\sigma}
\end{gathered}
$$

Pressure drop is one of the key thermodynamic performance of the evaporator. Given that the frictional pressure drop and partial pressure drop are the main factors, the frictional pressure drop correlation by Choi et al. ${ }^{[17]}$ and partial pressure drop correlation by Payne et al. ${ }^{[18]}$ are employed in this study. The correlation by Choi is given as

$$
\Delta P=\frac{f_{\text {tp }} L G^{2}}{d_{h}}\left(\frac{1}{\rho_{\text {in }}}+\frac{1}{\rho_{\text {out }}}\right)+G^{2}\left(\frac{1}{\rho_{\text {out }}}-\frac{1}{\rho_{\text {in }}}\right)
$$

where the $f_{\mathrm{tp}}$ is the friction factor, $\rho_{\text {in }}$ and $\rho_{\text {out }}$ are the inlet density and outlet density of the refrigerant, respectively, and $L$ is the total tube length.

The correlation by Payne et al. ${ }^{[18]}$ consists of a sudden enlargement and sudden contraction sections, which are given as

$$
\Delta P_{\mathrm{en}}=G^{2} \sigma(1-\sigma) v_{l}\left[1+\left(\frac{v_{t p}}{v_{l}}\right) x\right]
$$




$$
\Delta P_{\text {con }}=\frac{G^{2} v_{l}}{2}\left[\left(\frac{1}{C_{c}}-1\right)^{2}+\left(1-\frac{1}{\sigma^{2}}\right)\right]\left[1+\left(\frac{v_{t p}}{v_{l}}\right) x\right]
$$

where the $C_{c}$ is contraction coefficient.

$$
\mathrm{C}_{c}=\frac{A_{c}}{A}
$$

\subsection{Calculation procedure}

Some limitations are given to reduce the thermodynamic performance calculation process of the EFGE properly, as follows:

1. The evaporator is a single row, the tube number is set at 22 for 11 passes. The dimensions of the evaporator are listed in Table 1.

2. R22 is used, the evaporating temperature is assumed to be $280.15 \mathrm{~K}$ and the heat load is set at $1.0 \mathrm{~kW}$.

3. The high-quality flows generated by different quality distributors have the same quality.

4. The effect of pressure drop difference on the mass flux of different tubes in a pass is neglected.

The thermodynamic performance prediction method of the EFGE is shown in Fig.4. The main steps of thermodynamic performance prediction method are as follows:

a. Calculation at the first pass: the heat load and inlet vapor quality of pass $K=1$ are given, and the outlet quality of pass $K=1$ is obtained. Then, the in-tube HTC and pressure drop of pass $K=1$ are obtained.

b. Calculation with quality distribution: the different inlet qualities of the high-quality and low-quality flows are set, and the HTC and pressure drop of each flow are obtained. Then, the refrigerant properties and mass flux of the passes are based on the local. The steps are repeated until all the passes with quality distributions are considered.

c. The weighted average of the evaporation HTC is calculated, and the pressure drop of each pass is added.

\section{Experiments}

\subsection{Test apparatus}

Fig.5 shows the evaporator test apparatus. The apparatus consists of two loops: refrigerant circulation and air handling. After leaving the compressor, the refrigerant vapor goes through an oil separator and then a condenser. Subsequently, the vapor goes through a storage, a sight glass, an electronic flow meter, an expansion, a cooler, a 
spiral heating wire, a test evaporator, a superheater with spiral heating wire, and a liquid-vapor separator and finally returns to the compressor. The cold source of the cooler comes from the expansion at the bypass, which starts from the sight glass and reaches the back of the test evaporator. Refrigerant quality at the inlet of the test section can be regulated with a cooler and spiral heating wire, and the refrigerant at the outlet quality of the test section can be superheated by the superheater. The tested section is set up in an air channel. The air temperature at the inlet of the channel can be regulated with an air handling apparatus. Transducers measure the pressure of the refrigerant and that of air, and a platinum resistance thermometer records the temperatures of the refrigerant and air. A flow meter measures the air velocity in the air channel after the air flow is balanced through equalization. For the measurement of the diabatic temperature of the finned tube wall, 22 thermocouples are set on the finned tube walls in the middle of each tube to monitor diabatic wall temperature. Another 22 thermocouples are set on the copper tube with thermal insulation material that follow the adiabatic wall temperature of each pass. The detailed experimental procedure is as follows: After the test beginning, environment temperature is set at 298.15 $\mathrm{K}$ and self-controlled with an air preparation system. The deviation of the environment temperature is $\pm 0.5 \mathrm{~K}$. The frequency changer controls the compressor power. After heat exchange in the condenser, the refrigerant must be in full liquid phase in the sight glass. Then, the ultrasonic flowmeter measures the mass flux. By means of the expansion opening at main line, the mass flux is set at $340 \mathrm{kgm}^{-2} \mathrm{~s}^{-1}$. The expansion using deeper throttling at the bypass offers a cold source that cools the refrigerant before the test section. After the expansion opening at the bypass and spiral heating wire power at the main line are controlled, the quality at the inlet of the tested evaporator can be regulated. By controlling the air mass flux in the air tunnel, the heat load on the tested evaporator can be fixed, and the heat load on the test evaporator is obtained by the enthalpy-difference of air. By controlling the power of the spiral heating wire before the compressor, suction temperature and suction pressure can be regulated as required. When the refrigerant mass flux is $650 \mathrm{kgm}^{-2} \mathrm{~s}^{-1}$, compressor power should be added by frequency changer, and the expansion opening at the main line and that at the bypass should be regulated synergistically. When the test apparatus shows stable operation continuously for $25 \mathrm{~min}$, test data are collected and analyzed in real time. Table 2 lists the accuracy of the measuring apparatus, and Table 3 lists the operating conditions.

\subsection{Data reduction and uncertainty}

The following equations show the main data reduction and the experiment uncertainty. Transducer propagation uncertainty includes type-A and type-B uncertainty. The randomness of the measurements follows type-A, such as the wall thickness and tube length measurements, which are measured 20 times repeatedly and took a level of confidence of $95 \%(\mathrm{P}=95 \%)$. In terms of expanded uncertainty, the coverage factor $\mathrm{k}=2$. All the transducer uncertainties are determined through type-B.

\subsubsection{Pressure drop}




$$
\Delta P=P_{\text {in }}-P_{\text {out }}
$$

The uncertainty of pressure drop is

$$
U_{\Delta p}=\sqrt{\left(\frac{\partial \Delta P}{\partial P_{\text {in }}}\right)^{2} \times U_{P_{\text {in }}}^{2}+\left(\frac{\partial \Delta P}{\partial P_{\text {out }}}\right)^{2} \times U_{P_{\text {out }}}^{2}},(P=95 \%) .
$$

Thus, the maximum refrigerant pressure drop uncertainty is $\pm 1.66 \mathrm{kPa}$.

\subsubsection{Heat load}

The heat load of evaporator is calculated by air side, which is

$$
Q_{e}=\rho_{a} V_{a}\left(C_{p, \text { in }} T_{a, \text { in }}-C_{p, \text { out }} T_{a, \text { out }}\right)
$$

Thus, the uncertainty of heat load is

$$
U_{Q e}=\sqrt{\left(\frac{\partial Q_{e}}{\partial m_{a}}\right)^{2} U_{m_{a}}^{2}+\left(\frac{\partial Q_{e}}{\partial T_{a, \text { in }}}\right)^{2} U_{T_{a, \text { in }}}^{2}+\left(\frac{\partial Q_{e}}{\partial T_{a, \text { out }}}\right)^{2} U_{\text {Tout }}^{2}},(P=95 \%)
$$

The relative standard uncertainty of $Q_{\mathrm{e}}$ is $\pm 1.92 \%$.

\subsubsection{Average refrigerant quality}

The entrance refrigerant quality of evaporator is calculated by

$$
\chi_{\text {in }}=\left(I_{\text {pre }, l o}+Q_{R}-I_{l, s a t}\right) /\left(I_{v, s a t}-I_{l, s a t}\right)
$$

where $I_{\text {pre,lo }}$ is the enthalpy of refrigerant after the cooler, $Q_{R}$ is the heat load on the spiral heating wire, and $I_{v, s a t}$ and $I_{l, s a t}$ are the enthalpies of the saturation vapor and saturation liquid based on the average boiling temperatures of the evaporator, respectively. The refrigerant properties are determined using REFPROP 7.0.

The outlet quality is calculated by

$$
\chi_{\text {out }}=Q_{e} /\left(I_{v, \text { sat }}-I_{l, s a t}\right)+\chi_{\text {in }}
$$

The average refrigerant quality can be calculated by

$$
\chi_{m}=\left(\chi_{\text {in }}-\chi_{\text {out }}\right) / 2
$$

3.2.4 Average heat transfer coefficient

$$
h_{i, m}=Q_{e} /\left[A_{i}\left(T_{r, m}-T_{w, m}\right)\right]
$$


Thus, the HTC uncertainty is calculated as follows:

$$
U_{h i}=\sqrt{\left(\frac{\partial h_{i}}{\partial Q_{e}}\right)^{2} U_{Q e}^{2}+\left(\frac{\partial h_{i}}{\partial A_{i}}\right)^{2} U_{A_{i}}^{2}+\left(\frac{\partial h_{i}}{\partial T_{r}}\right)^{2} U_{T_{r}}^{2}+\left(\frac{\partial h_{i}}{\partial T_{w}}\right)^{2} U_{T_{w}}^{2}},(P=95 \%)
$$

Finally, the maximum relative uncertainty of the boiling HTC is $\pm 6.8 \%$.

\subsubsection{Friction power reduction}

Friction power reduction (FPR) is used in ranking the thermodynamic performance of the EFGE and PFE, the form of the FPR is as follows ${ }^{[19]}$ :

$$
\begin{gathered}
P_{E F G E}^{\prime \prime} / P_{P F E}^{\prime \prime}=\left(f_{E F G E} / f_{P F E}\right) /\left(N u_{E F G E} / N u_{P F E}\right)^{3} \\
f=\Delta P D \rho / 2 L G^{2}
\end{gathered}
$$

Thus, the FPR uncertainty is calculated as follows:

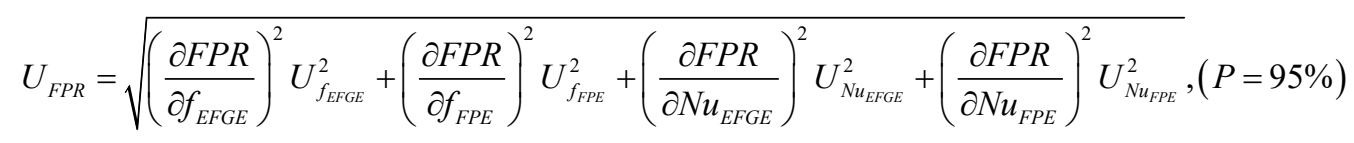

Finally, the maximum relative uncertainty of the FPR is $\pm 7.9 \%$.

\subsubsection{Minimum entropy generation number}

The minimum entropy generation (NS) proposed by Saechan is also employed to rank the thermodynamic performance of the EFGE and the PFE, which is expressed as ${ }^{[20]}$ :

$$
N S=\left(S_{\text {gen, }, a}+S_{g e n, r}\right) /\left(C_{p} m\right)_{a}
$$

where $S_{\text {gen,a }}$ is the entropy generation rate on the air side, and $S_{\text {gen,r }}$ is the entropy generation rate on the refrigerant side, which is calculated by

$$
\begin{gathered}
S_{\text {gen }, a}=\left(m C_{\mathrm{p}}\right) a \ln \left(T_{a, o} / T_{a, i}\right)-(m R)_{a} \ln \left(P_{a, o} / P_{a, i}\right) \\
S_{g e n, r}=S_{r, \text { out }}-S_{r, \text { in }}
\end{gathered}
$$

Thus, the NS uncertainty is calculated as follows:

$$
U_{N s}=\sqrt{\left(\frac{\partial N S}{\partial S_{\text {gen }, a}}\right)^{2} U_{S_{g e n, a}}^{2}+\left(\frac{\partial N S}{\partial S_{g e n, r}}\right)^{2} U_{S_{g e n, r}}^{2}+\left(\frac{\partial N S}{\partial m_{a}}\right)^{2} U_{m_{a}}^{2}},(P=95 \%)
$$

Finally, the maximum relative uncertainty of the NS is $\pm 7.3 \%$. 


\section{Results}

\subsection{Theoretical calculation results}

Fig.6 shows the refrigerant mass flux in each pass of the PFE and the EFGE at an inlet mass flux of 340 $\mathrm{kgm}^{-2} \mathrm{~s}^{-1}$. The mass fluxes in the tubes of the PFE are constant at each pass. The mass fluxes of the EFGE are studied when the inlet quality of the high-quality flow is $0.5,0.7$, or 0.9 . From the first pass to the eighth pass, the mass flux of the high-quality flow at quality of 0.5 increases 3.9 times, the mass flux of the high-quality flow at quality of 0.7 increases 5.3 times, and the mass flux of the high-quality flow at quality of 0.9 increases 6.2 times. Conversely, the mass flux of the low-quality flow (quality is set at $0.0 \%$ ) in each pass decreases continuously. The mass flux of the low-quality flow is 2.6-5.9 times that of the high-quality flow at the first pass and is $54.4 \%$ less than that of the high-quality flow at the eighth pass. From the first pass to the eighth pass, the mass flux of the low- and high-quality flows tend to be uniform. The largest mass flux of the low-quality flow at the first pass is 0.67 times that of the PFE, and the least mass flux of the high-quality flow at the first pass is $24.3 \%$ of that of the PFE. Thus, the mass flux of the EFGE is nonuniform in few passes but is acceptable from application in most passes.

Fig.7 is the mass flux in each pass of both evaporators at an inlet mass flux of $650 \mathrm{kgm}^{-2} \mathrm{~s}^{-1}$. At the first pass, the mass flux of low-quality flow is $2.8-6.2$ times that of the high-quality flow while the mass flux of low quality flow are about $55.6 \%$ less than those of the high-quality flow at the eighth pass. The largest mass flux of the low quality flow at the first pass is 0.72 times more than that of the PFE, and the least mass flux of the high-quality flow at the first pass is $23.5 \%$ of that of the PFE. The results show that the uniformity of the mass flux drops slightly as the inlet mass flux increases. The reason is that increasing inlet mass flux leads to less uniform heat load at different passes.

Fig. 8 shows the HTC in each pass of the PFE and EFGE at an inlet mass flux of $340 \mathrm{kgm}^{-2} \mathrm{~s}^{-1}$. From the first pass to the eighth pass, the HTC of the PFE increases slightly. In the ninth pass, the HTC of the PFE starts to increases considerably. Given that the average quality is 0.75 at the ninth pass, fully nucleate boiling is maintained until the eleventh pass. The HTC of the EFGE with high-quality flow at quality $0.5,0.7$, or 0.9 is studied. From the first pass to the eighth pass, the HTC values of the high-quality flow at quality of 0.5 are $0.25-0.44$ times and those at quality of 0.9 are $1.42-1.98$ times those of the PFE. The HTC values of the low-quality flow at quality of 0.5 are $27 \%-121 \%$ and those at quality of 0.9 are $26 \%-131 \%$ of those of the PFE. However, the average HTC values of the high- and low-quality flow at quality of 0.5 are $85 \%-122 \%$ and those at quality of 0.9 are $134 \%-$ $204 \%$ those of the PFE. The results indicate that a high-quality flow with low quality may drop the HTC of the

EFGE, but a high-quality flow with high quality, such as 0.9, can improve the HTC of the EFGE. High-quality flow heat transfer with fully nucleate boiling occurs at all passes, and thus a considerable amount of refrigerant 
shows a high-efficiency boiling heat transfer flow pattern earlier than expected.

Fig.9 is the HTC in each pass of the PFE and EFGE at an inlet mass flux of $650 \mathrm{kgm}^{-2} \mathrm{~s}^{-1}$. From the first pass to the eighth pass, the HTC of the high-quality flow at quality of 0.5 is $0.12-0.37$ times and that at quality of 0.9 is $0.46-0.81$ times that of the PFE. The HTC of the low-quality flow at quality of 0.5 are $32 \%-115 \%$ and that at quality of 0.9 is $29 \%-127 \%$ that of the PFE. However, the average HTC values of the high- and low-quality flows at quality of 0.5 are $85 \%-114 \%$ and those at quality of 0.9 are $138 \%-189 \%$ of those of the PFE. At a high inlet mass flux, the rate of increase of the HTC of the EFGE drops slightly. Because with the increasing inlet mass flux, more passes of the PFE form high-efficiency boiling heat transfer flow pattern.

Fig.10 is the pressure drop in each pass of the PFE and the EFGE at inlet mass flux $340 \mathrm{kgm}^{-2} \mathrm{~s}^{-1}$. The pressure drop of the PFE increases as the pass number increases, so is the EFGE. From the first pass to the fifth pass, the high-quality flow pressure drop of the EFGE at quality 0.5 are 0.89 to 1.56 times of those of the PFE, those of the high-quality flow at quality 0.9 are 0.65 to 1.31 times. The pressure drop of the low quality flow at quality 0.5 are $34 \%$ to $123 \%$ of those of the PFE, while they are $28 \%$ to $169 \%$ at quality 0.9 . It is interesting that the average pressure drop of high- and low-quality flows at quality of 0.5 are $94 \%-106 \%$ of those of the PFE, by $80 \%-116 \%$ at quality 0.9. The advantage of the average pressure drop for EFGE increases with the number of passes. The results indicate that the EFGE with high-quality flow at low quality has a larger average pressure drop than the PFE, but the average pressure drop of the EFGE with high-quality flow at high quality has an obvious advantage over that of the PFE. Owing to low quality, the mass flux of the low-quality flow is much larger than that of the PFE, the shear force between a liquid and a wall is conspicuous, and the mass flux of the high-quality flow is larger than that of the PFE at high quality. With increase in the number of passes, the pressure drop difference between the high- and low-quality flows drop first and then increases for the EFGE. The reason is the mass flux change in the tubes as the number of passes increases.

Fig.11 shows the pressure drop in each pass of the PFE and EFGE at an inlet mass flux of $650 \mathrm{kgm}^{-2} \mathrm{~s}^{-1}$. From the first pass to the fifth pass, the high-quality flow pressure drop of the EFGE at quality of 0.5 is $0.71-1.48$ times and that at quality of 0.9 are $0.52-1.14$ times that of the PFE. The pressure drop of the low-quality flow at quality of 0.5 is $48 \%-119 \%$ and that at quality of 0.9 is $39 \%-160 \%$ of that of the PFE. The average pressure drop of the high- and low-quality flows at quality of 0.5 is $95 \%-102 \%$ of those of the PFE and quality of 0.9 is $77 \%-108 \%$. Compared with the results at a mass flux of $340 \mathrm{kgm}^{-2} \mathrm{~s}^{-1}$, the EFGE owns larger advantage on average pressure drop than those of the PFE when the mass flux increases. Because the mass flux at large-scale, the effect of the mass flux on the pressure drop reduces and the effect of the vapor quality grows.

4.2 Experimental results

\subsubsection{Heat transfer coefficient and pressure drop}


The average HTC and total pressure drop of both evaporators are tested, and the results are used in validating the theoretical results. The evaporating temperature is $280.15 \mathrm{~K}$, the average quality is $0.5-0.95$, and the inlet mass flux is set at 340 and $650 \mathrm{kgm}^{-2} \mathrm{~s}^{-1}$. Fig.12 shows the average HTC of both evaporators. At experimental mass flux, the average HTC of the PFE increases by $112 \%$ when average quality change is $0.5-0.9$, but a small drop is observed when the average quality continuously increases to 0.95. The average HTC of the EFGE increases by $52 \%-76 \%$ when the average quality change is $0.5-0.9$. At an average quality of $0.5-0.8$, the average HTC of the EFGE is $15 \%-32 \%$ higher than that of the PFE, but their peaks are nearly the same at quality of 0.9 . Owing to the quality distributor, the EFGE achieves the high-efficiency evaporation of high-quality flows, and the high-efficiency evaporation of both evaporators have little changes at a high quality (approximately 0.9). When the inlet mass flux increases from $340 \mathrm{kgm}^{-2} \mathrm{~s}^{-1}$ to $650 \mathrm{kgm}^{-2} \mathrm{~s}^{-1}$, the average HTC of the EFGE increases by $19 \%-$ $40 \%$. The results indicate that the EFGE can substantially improve the average HTC at a low quality. The growth between the tested HTC and the theoretical HTC are similar at quality of 0.5-0.8. However, the values differ obviously at quality of $0.8-0.95$. At a mass flux of $340 \mathrm{kgm}^{-2} \mathrm{~s}^{-1}$, the theoretical HTC provides a maximum deviation of $\pm 17.7 \%$ to the experimental results. At an inlet mass flux of $650 \mathrm{kgm}^{-2} \mathrm{~s}^{-1}$, a maximum deviation of $\pm 15.6 \%$ to the experimental results is obtained. Overall, the heat transfer coefficient correlation by Kanizawa ${ }^{[15]}$ accurately predicts the experimental results.

Fig.13 shows the total pressure drops in both evaporators. These experimental pressure drops verify the theoretical pressure drops. At an experimental mass flux, the total pressure drop of the EFGE increase 1.19 times when the average quality change ranges from 0.5 to 0.95 and 0.85 times that for the PFE. At average quality of 0.5 , the total pressure drop of the EFGE is $13 \%-15 \%$ lower than those of the PFE but $1 \%-3 \%$ higher than that of the PFE at quality of 0.95 . The reason may be that the EFGE achieves high- and low-quality flows through quality distribution at low quality. The shear force between liquid and vapor is reduced obviously, and difference in shear force between the EFGE and PFE is negligible at high quality, but resistance in the quality distributor increases. When the inlet mass flux increases from $340 \mathrm{kgm}^{-2} \mathrm{~s}^{-1}$ to $650 \mathrm{kgm}^{-2} \mathrm{~s}^{-1}$, the total pressure drop of the EFGE increases from $50 \%$ to $66 \%$. The results indicate that the EFGE can reduce pressure drop at low quality but may lead to a large pressure drop at a high-quality area. The growth between the tested pressure drop and theoretical

pressure drop are similar at inlet mass flux of $340-650 \mathrm{kgm}^{-2} \mathrm{~s}^{-1}$, but the deviation becomes large when quality increases. At an inlet mass flux of $340 \mathrm{kgm}^{-2} \mathrm{~s}^{-1}$, the theoretical pressure drop provides a maximum deviation of $\pm 15.7 \%$ to the experimental results. At an inlet mass flux of $650 \mathrm{kgm}^{-2} \mathrm{~s}^{-1}$, a maximum deviation of $\pm 13.1 \%$ to the experimental results is obtained. The results indicate that the pressure drop calculated by Choi et al. ${ }^{[17]}$ and Payne et al. ${ }^{[18]}$ also accurately predicts the experimental results.

\subsubsection{Evaluation}

Minimum entropy generation number (NS) and friction power reduction (FPR) are used in ranking the 
thermodynamic performance of the EFGE and PFE. The thermodynamic performance of the evaporator improves with decreasing NS. As shown in Fig.14, the NS of both evaporators increase with quality, and the NS of the EFGE is $4 \%-16 \%$ lower than that of the PFE at quality $0.5-0.8$ but is $4 \%-7 \%$ higher than that of the PFE at quality 0.9-0.95. The reason is that the average HTC of the EFGE is higher than that of the PFE and pressure drop of the EFGE is lower than that of the PFE at low quality, but the pressure drop of the EFGE is slightly larger than that of the PFE at quality of $0.9-0.95$.

Fig.15 shows the FPR for both evaporators. When the FPR is less than 1.0, the thermodynamic performance of the EFGE is better than that of the PFE. However, the thermodynamic performance of the EFGE is worse than that of the PFE, whereas the FPR is more than 1.0. At an inlet mass flux of $340 \mathrm{kgm}^{-2} \mathrm{~s}^{-1}$, quality increases from 0.5 to 0.95 , and FPR increases from 0.48 to 0.92 . At an inlet mass flux of $650 \mathrm{kgm}^{-2} \mathrm{~s}^{-1}$, the FPR increase from 0.59 to 1.08 with increasing quality. The results of the FPR indicate that the EFGE has better thermodynamic performance than the PFE at a large low-quality area, and the thermodynamic performance of the EFGE may be worse than that of the PFE when the quality is close to 1.0. The NS and the FPR results indicate that the thermodynamic performance of the EFGE is better than that of the PFE only at a large low-quality area and the increase in mass flux reduces the thermodynamic performance of the EFGE.

\section{Conclusion}

This study analyzes the thermodynamic performance of a novel efficient flow pattern global construction evaporator through numerical and experimental methods. According to the experimental results, minimum entropy generation number and friction power reduction are used in ranking the thermodynamic performance of the EFGE and PFE. The following conclusions are made:

1. Compared with the experimental results, the thermodynamic performance prediction by the novel numerical method of the EFGE is following well generally. Thus, the method effectively optimizes the structure of the EFGE.

2. The average HTC of the EFGE greatly surpasses that of the PFE at a large low-quality area, and quality distribution can enhance evaporation HTC at low quality.

3. The pressure drop of the EFGE is slightly lower than that of the PFE at a large low-quality area but surpasses that of the PFE when the quality is close to saturation. The EFGE cannot reduce pressure drop when the mass flux has large-scale increases.

4. The thermodynamic performance of the EFGE is superior to that of the PFE according to the minimum entropy generation number and friction power reduction. However, the thermodynamic performance of the EFGE considerably decreases with increasing mass flux and quality. 
Acknowledgements

We gratefully acknowledge the Natural Science Foundation of Guangdong Province NO. 2018A030310026, the Natural Science Foundation of Guangdong Province NO.2114050002858, the Excellent Talents Specialized Research Project in University NO.KA180530505

Reference

[1] Sempértegui-Tapia D F, Ribatski G. Flow boiling heat transfer of R134a and low GWP refrigerants in a horizontal micro-scale channel[J]. International Journal of Heat and Mass Transfer. 2017, 108 : 2417-2432.

[2] Su X, Chen X, Zhang Q, et al. Experimental study on heat transfer characteristics of LN 2, saturated flow boiling in a horizontal corrugated tube[J]. Experimental Thermal \& Fluid Science, 2017, 80:259-269.

[3] Jo C U, Lee D C , Chung H J , et al. Comparative evaluation of the evaporation heat transfer characteristics of a low-GWP refrigerant R-1234ze(E) between shell-and-plate and plate heat exchangers[J]. International Journal of Heat and Mass Transfer, 2020,153:1-10.

[4] Bustamante J G , Garimella S , Hughes M . Falling-Film Evaporation over Horizontal Rectangular Tubes: Part I-Experimental Results[J]. International Journal of Refrigeration, 2020,119:37-47.

[5] Li H, Hrnjak P. Effect of periodic reverse flow on the heat transfer performance of microchannel evaporators[J]. International Journal of Refrigeration, 2017,84:309-320.

[6] Dione K R, Louahlia H, Marion M, et al. Evaporation heat transfer and pressure drop for geothermal heat pumps working with refrigerants $\mathrm{R} 134 \mathrm{a}$ and $\mathrm{R} 407 \mathrm{C}[\mathrm{J}]$. International Communications in Heat \& Mass Transfer, 2018, 93:1-10.

[7] Jin P, Zhang Z, Ibrahim M, et al. Experimental Study of Falling Film Evaporation in Tube Bundles of Doubly-Enhanced, Horizontal Tubes. Applied Thermal Engineering, 2020, 170: 1-11.

[8] Tang H, Zhang T, Liu X. Experimental Study on Refrigerant Maldistribution in a Fin-and-Tube Evaporator for a Direct Expansion Air-Conditioning System. Energy and Buildings, 2020, 208: 1-10.

[9] Song K S, Yun S, Lee D C, et al. Evaporation Heat Transfer Characteristics of R-245fa in a Shell and Plate Heat Exchanger for Very-High-Temperature Heat Pumps. International Journal of Heat and Mass Transfer, 2020, 151: 1-10.

[10]. Shafaee M, Mashouf H, Sarmadian A, et al. Evaporation heat transfer and pressure drop characteristics of R-600a in horizontal smooth and helically dimpled tubes[J]. Applied Thermal Engineering, 2016, 107:28-36. 
[11]. Tang J, Sun L, Du M, et al, Experimental investigation of transition process from nucleate boiling to microbubble emission boiling under transient heating modes[J]. AIChE Journal, 2019, 65(5):1-13.

[12] Zhong T, Zhuo X, Liang J, et al. Double-dryness shunting and heat exchange evaparator[P], China, ZL201710208167.0, 2017.

[13] Zhong T, Liu Y, Chen P, et al, Study on heat pump system with substitution of different quality split-flow evaporator, Journal of the Harbin University of Commerce, 2020, 36(3):357-364.

[14] Nukiyama S. The maximum and minimum values of the heat $\mathrm{Q}$ transmitted from metal to boiling water under atmospheric pressure[J]. International Journal of Heat and Mass Transfer, 1966, 9(12): 1419-1433.

[15] Kanizawa F T, Tibiriçá C B, Cristiano Bigonha, et al. Heat transfer during convective boiling inside microchannels[J]. International Journal of Heat and Mass Transfer, 2016, 93:566-583.

[16] Fang X, Zhuang F, Chen C, et al. Saturated flow boiling heat transfer: review and assessment of prediction methods[J]. Heat and Mass Transfer, 2019, 55:197 - 222.

[17] Choi J Y, Kedzierski M A, Domanski P A. Generalized pressure drop correlation for evaporation and condensation in smooth and micro-fin tubes[J]. Proceedings of IIF-IIR Commision B, 2001, 1: 9-16.

[18] Payne W T, Nino V G, Hrnjak P S, et al, Void Fraction and Pressure Drop in Microchannels, ACRCTR-178, December 2000 .

[19] Webb RI, Eckert ERG. Application of rough surfaces to heat exchanger design, International Journal of Heat and Mass Transfer 1972, 15: 1647-1658.

[20] Saechan P, Wongwises S, Optimal configuration of cross flow plate finned tube condenser based on the second law of thermodynamics. International Journal of Thermal Sciences 2008,47:1473-1481. 


\section{Figures}

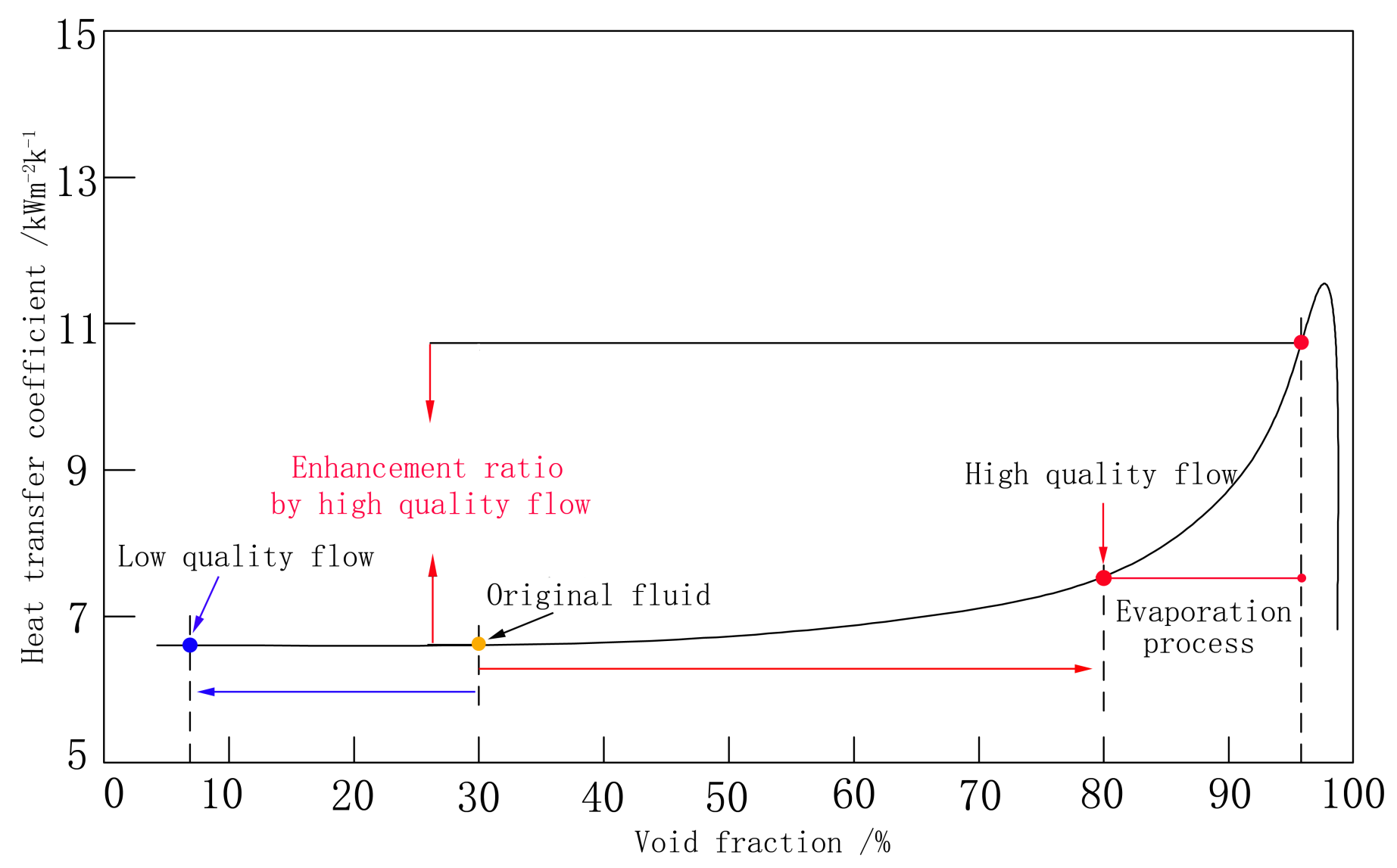

Figure 1

In an original flow at a quality 0.3 , the original flow is separated to a flow with a high quality of approximately 0.8 and a flow with a low quality of approximately 0.09 , as shown in Fig. 1.
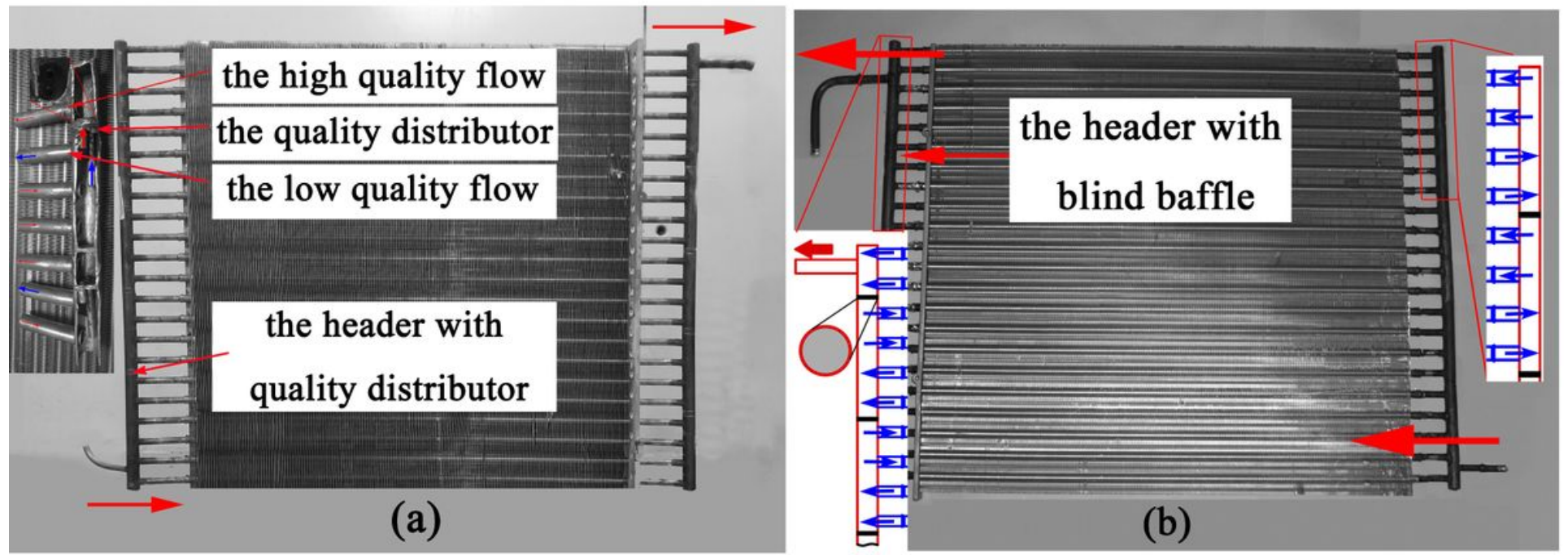
Figure 2

Fig. 2 is the EFGE based on the efficient flow pattern global construction heat transfer enhancement mechanism

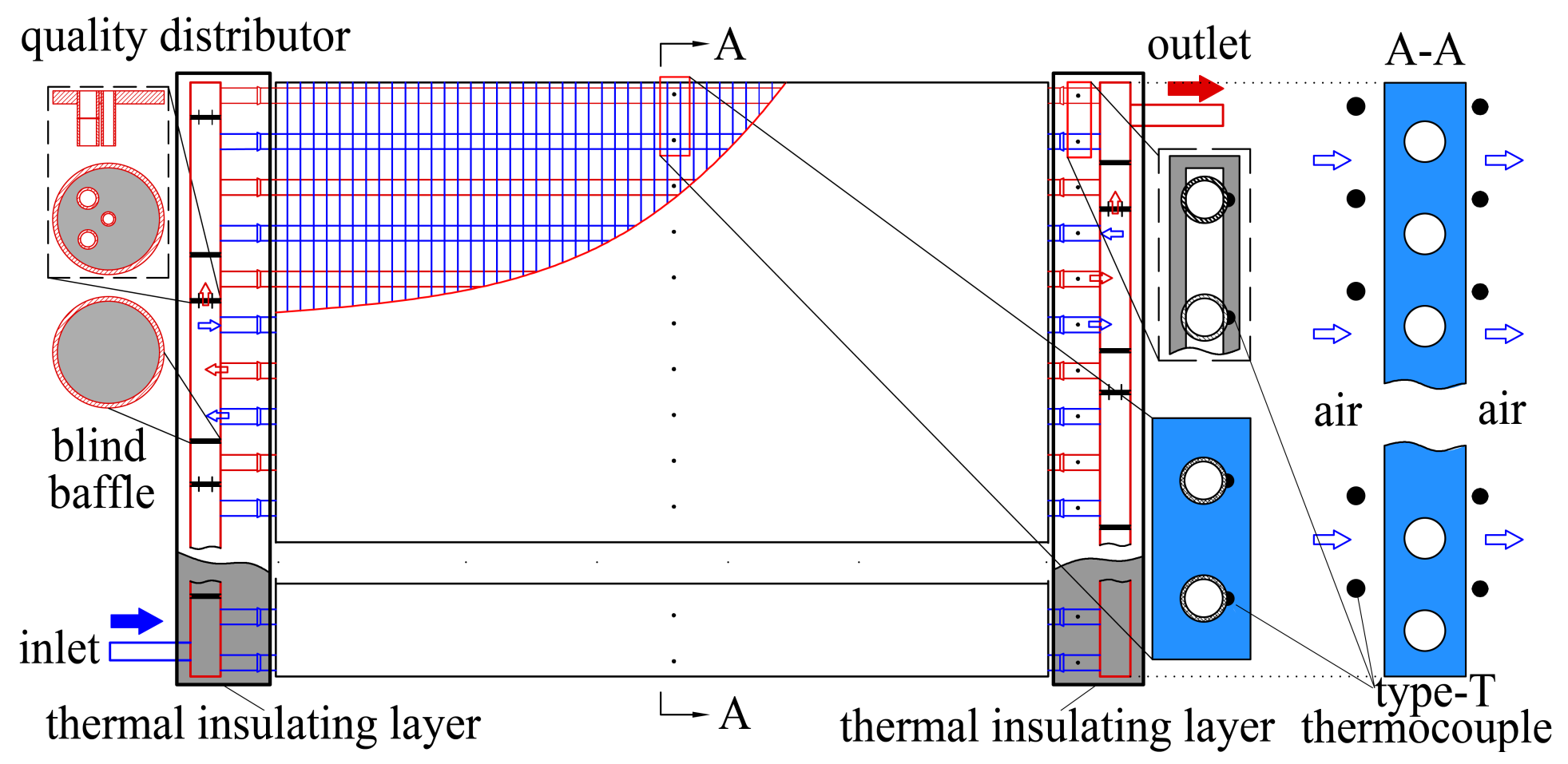

Figure 3

Fig.3 presents the block diagram of the EFGE and indicates the details in the experiment. 


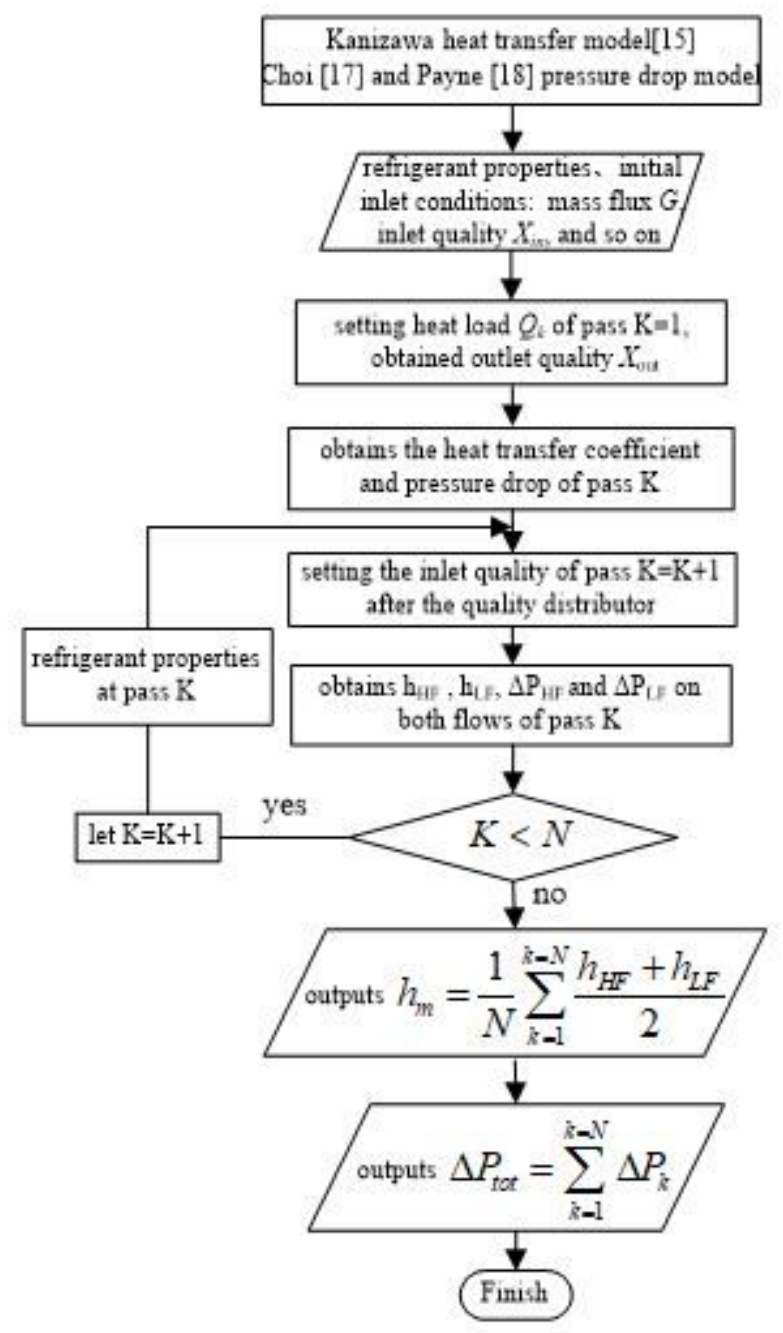

Figure 4

Thermodynamic performance prediction method of the EFGE 


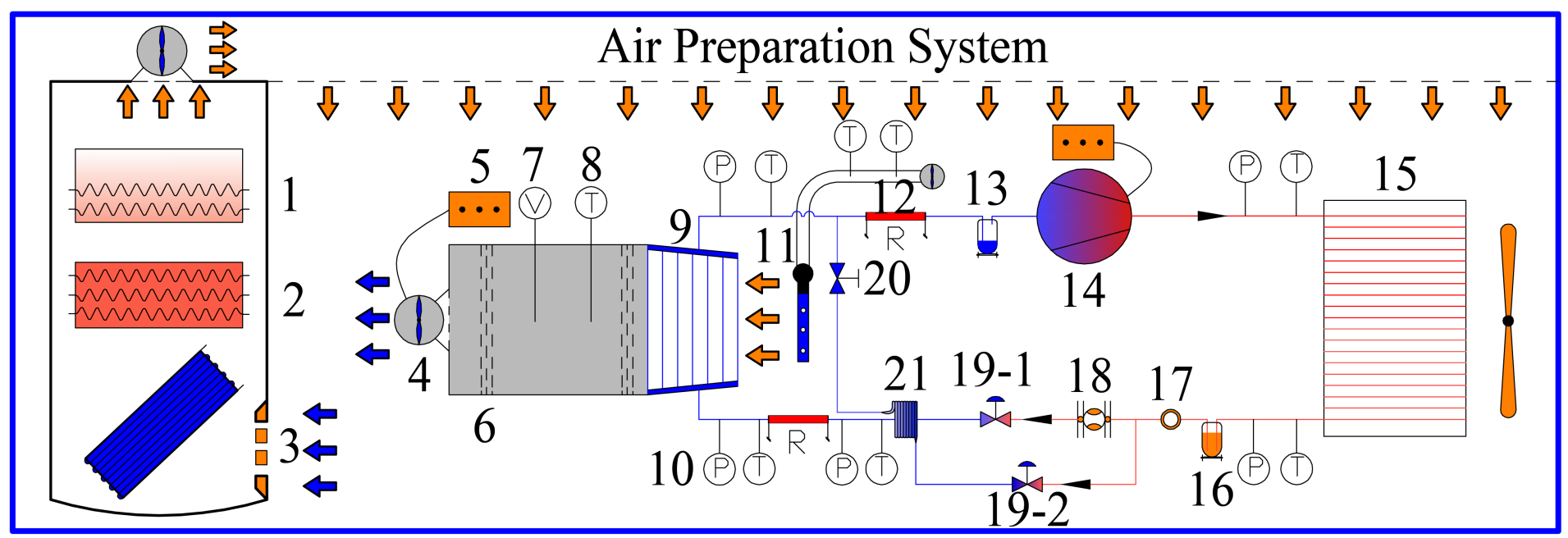

1.humidifier 2.heater 3.cooler 4.fan 5.frequency changer 6.equalization 7.flow meter 8.thermometer 9.tested evaporator 10.pressure gauge 11.sampler 12.spiral heating wire 13.liquid-vapor separator 14.compressor 15.condenser 16.storage 17.sight glass 18.ultrasonic flowmeter 19.expansion 20.valve 21.cooler

Figure 5

Fig.5 shows the evaporator test apparatus.

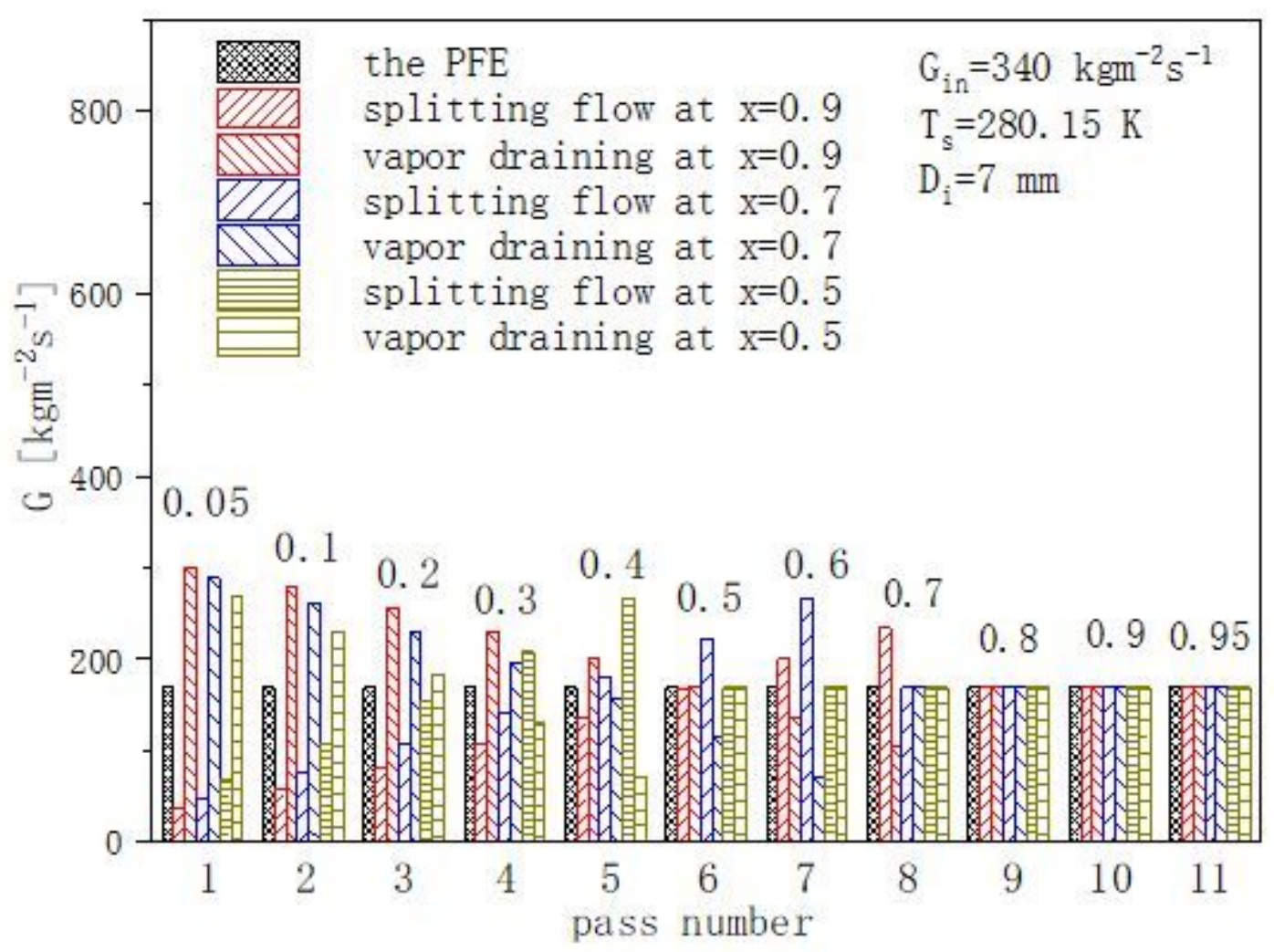

Figure 6 
The mass flux in each pass (Gin=340 kgm-2s-1)

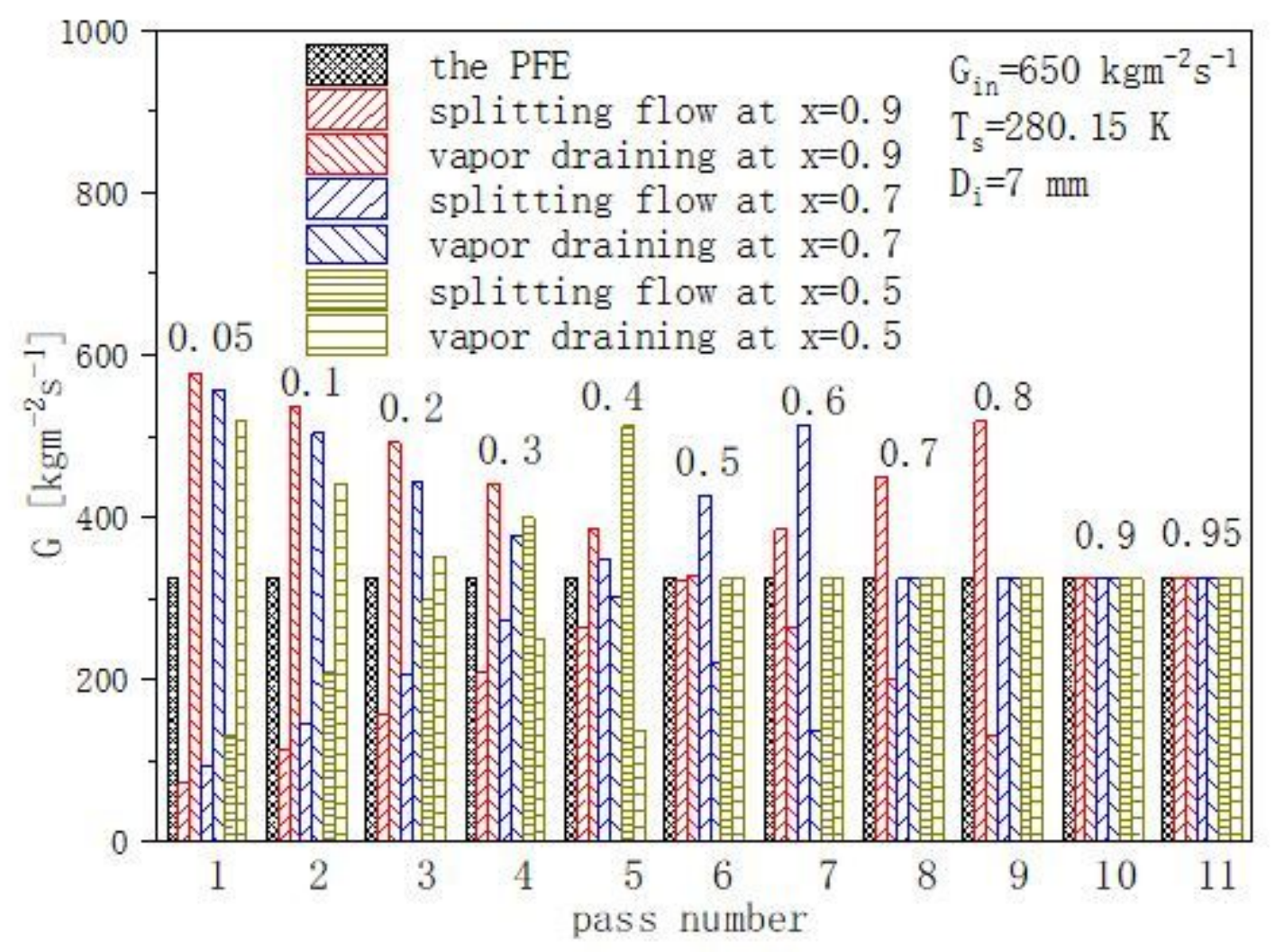

Figure 7

The mass flux in each pass (Gin=650 kgm-2s-1) 


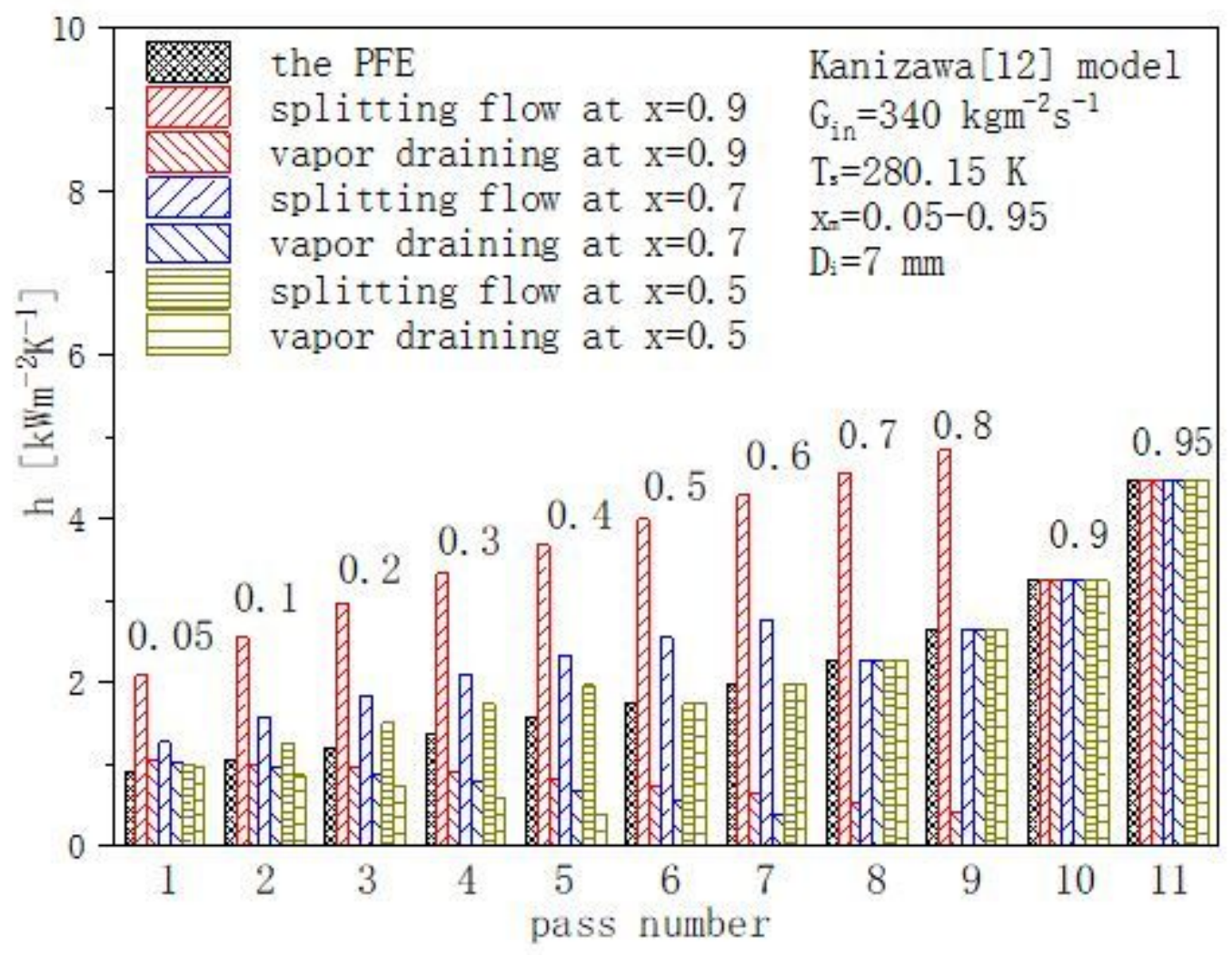

Figure 8

The HTC in each pass (Gin=340 kgm-2s-1) 


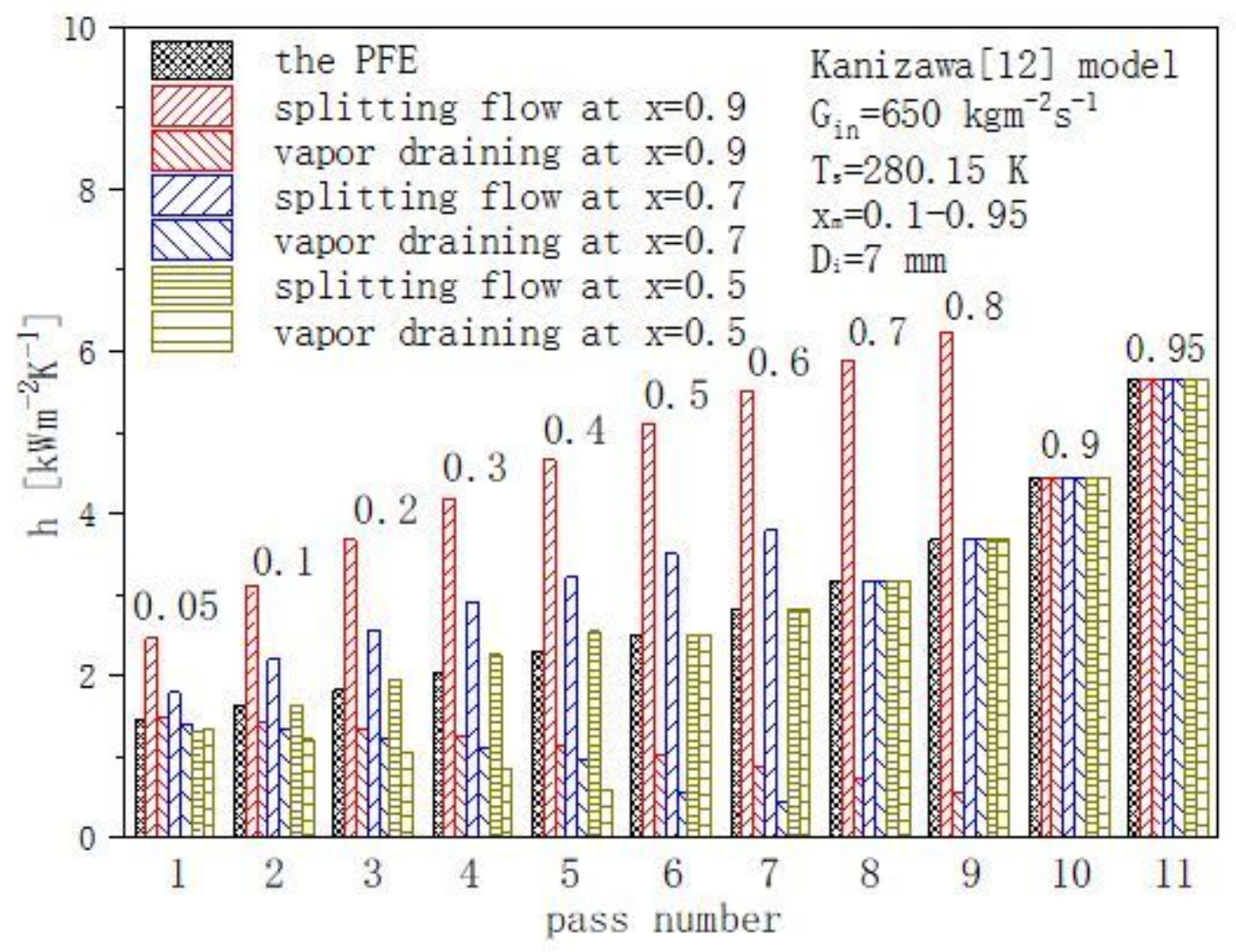

Figure 9

The HTC in each pass (Gin=650 kgm-2s-1) 


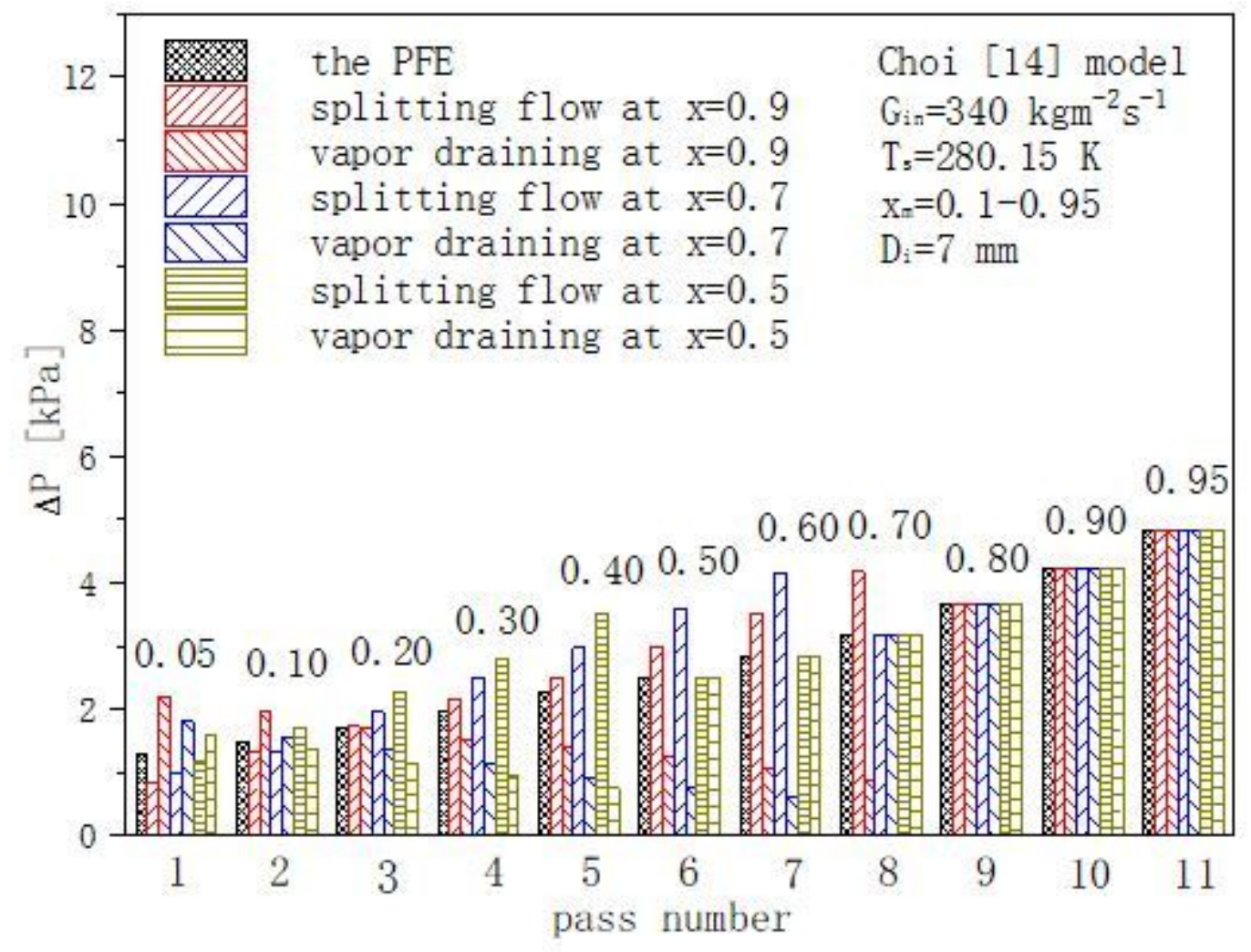

Figure 10

The pressure drop in each pass ( $\mathrm{Gin}=340 \mathrm{kgm}-2 \mathrm{~s}-1$ ) 


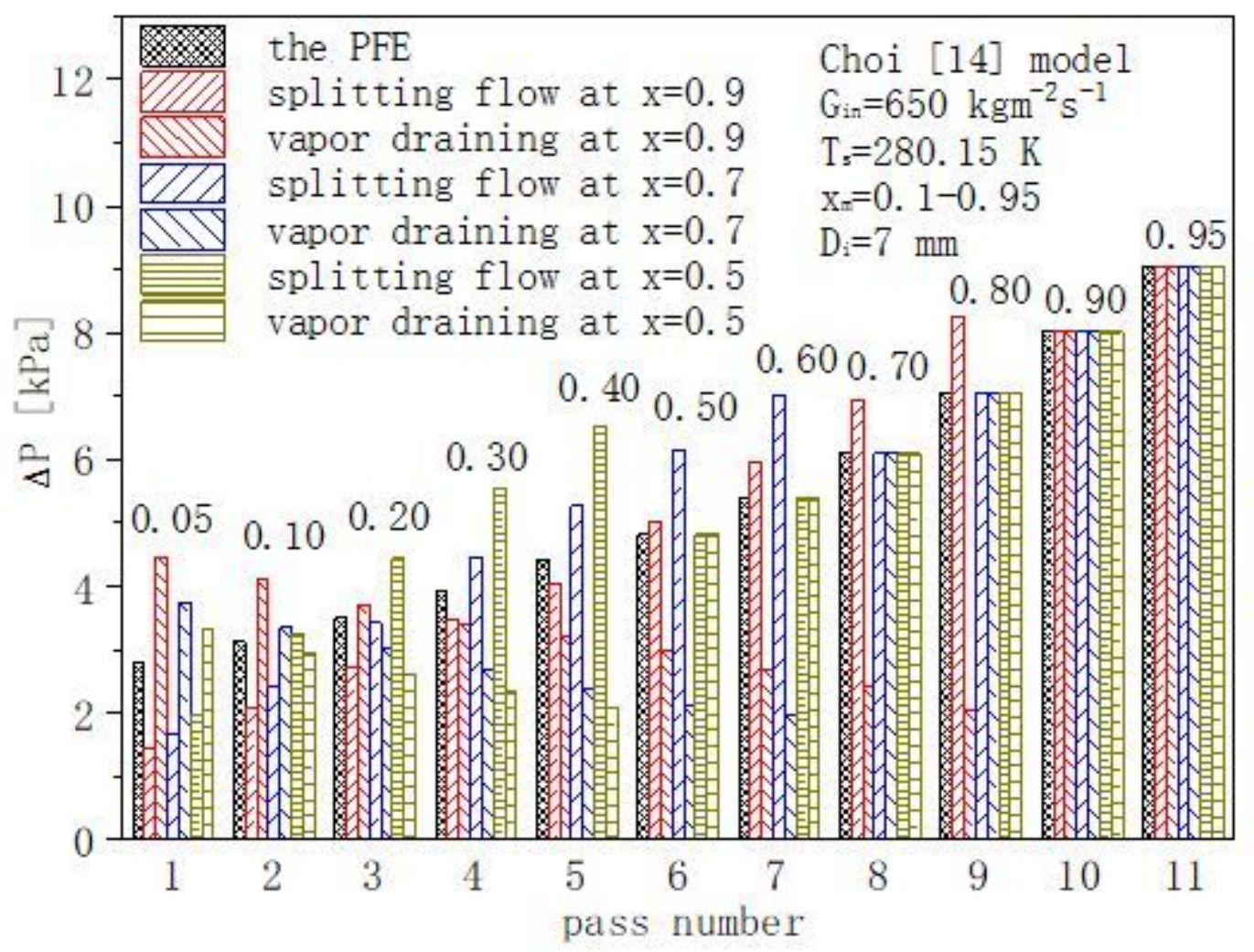

Figure 11

The pressure drop in each pass(Gin=650 kgm-2s-1) 


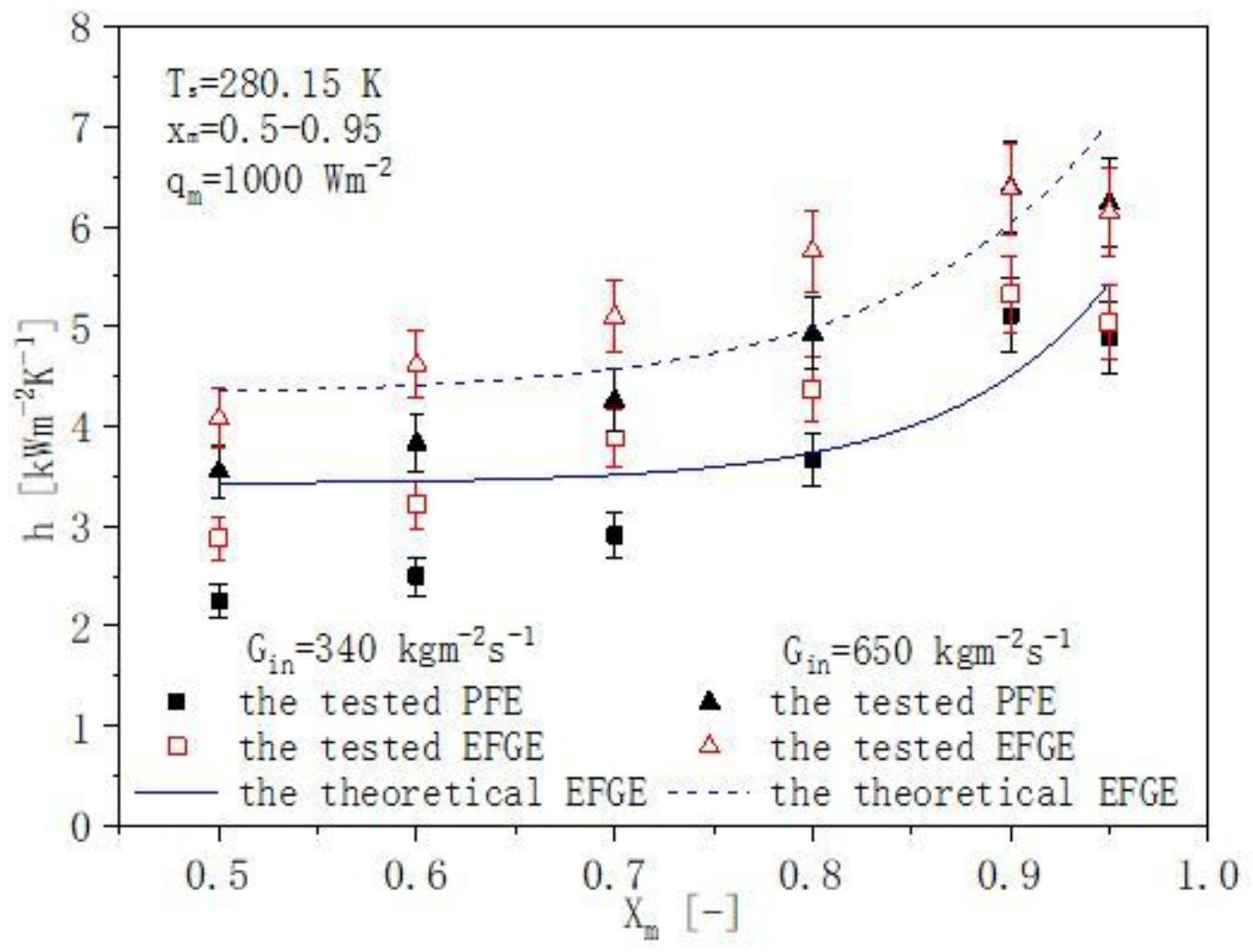

Figure 12

The experimental HTC of both evaporators 


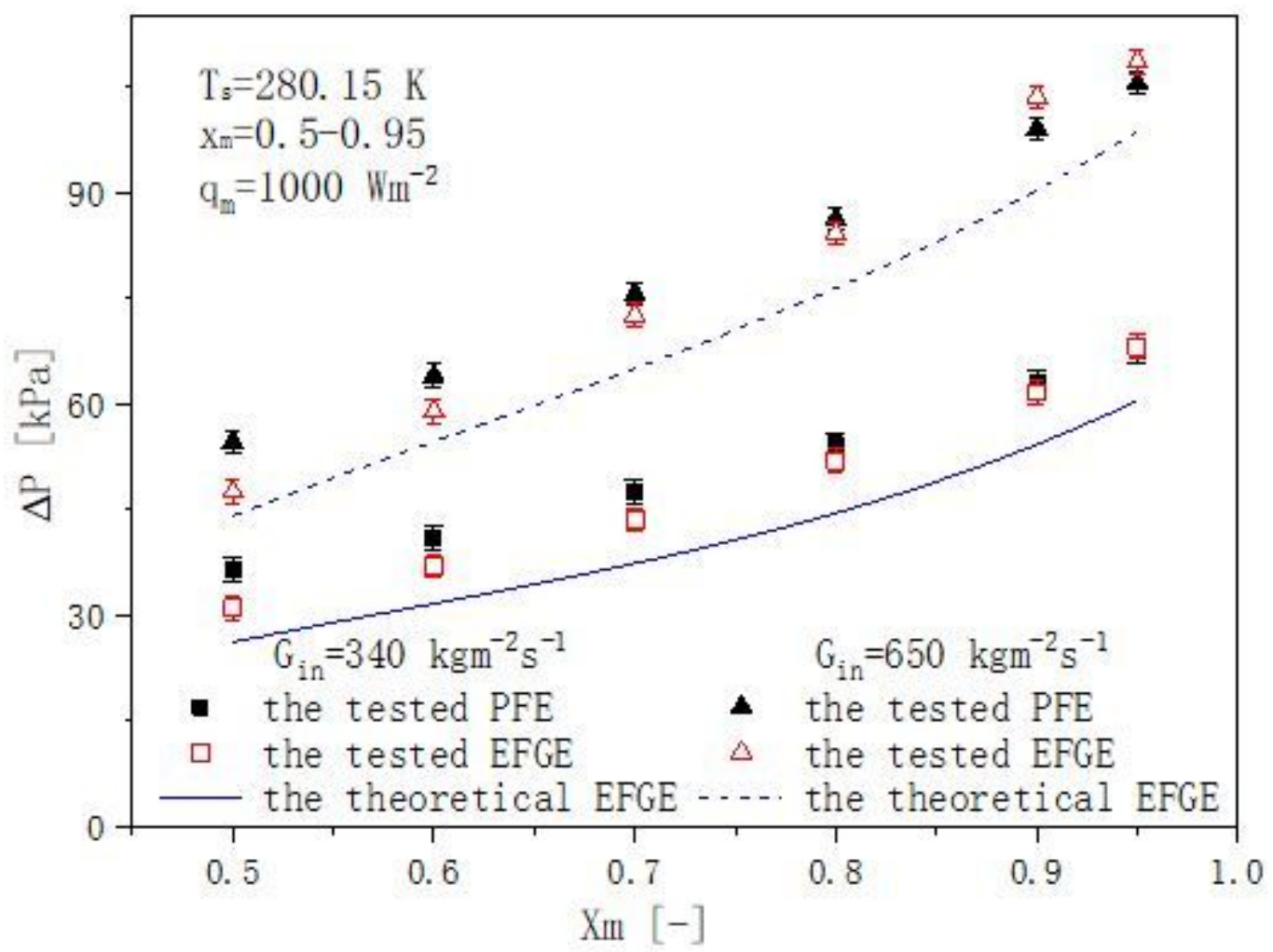

Figure 13

The experimental pressure drop of both evaporators 


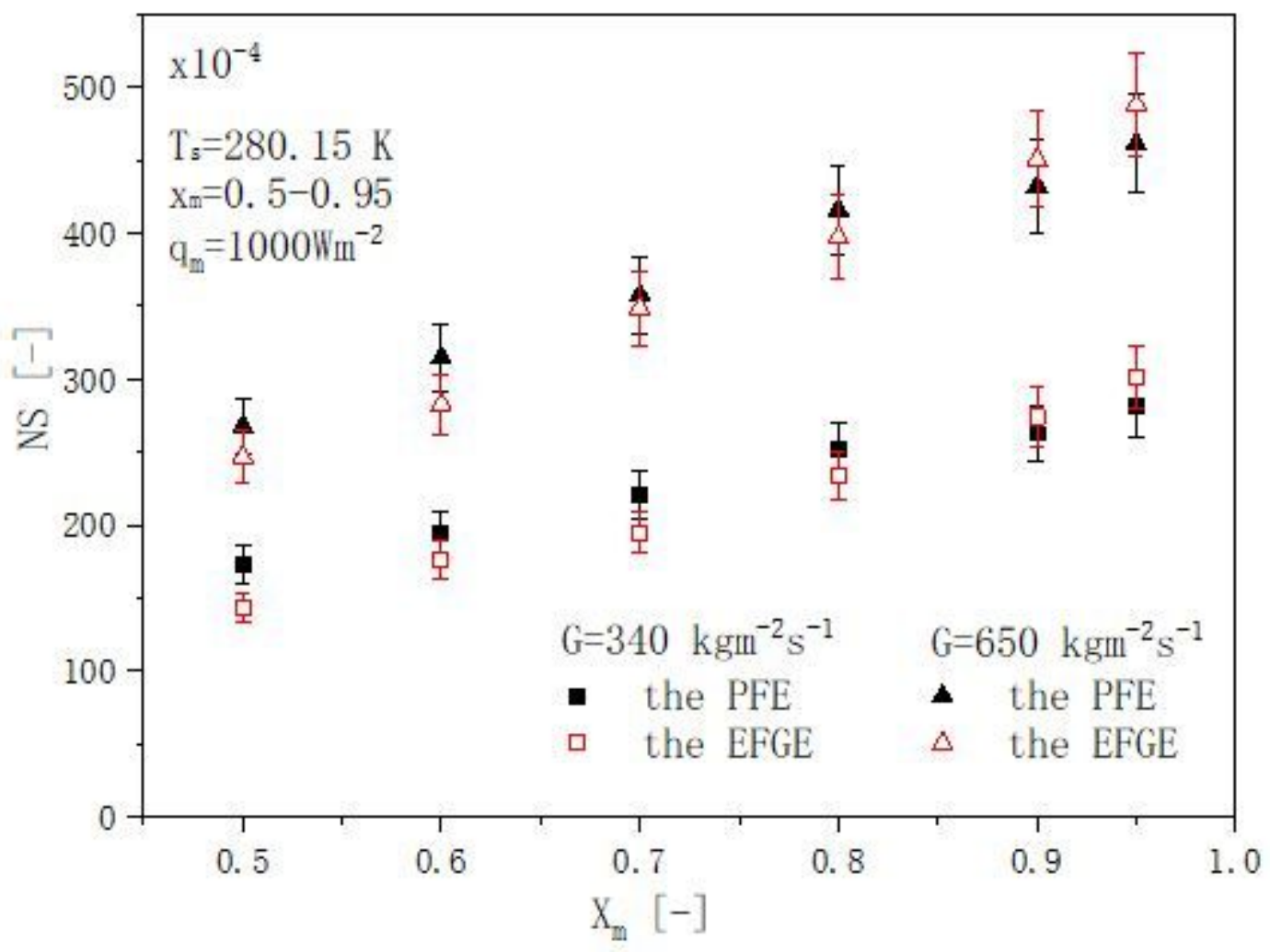

Figure 14

The NS of both evaporators

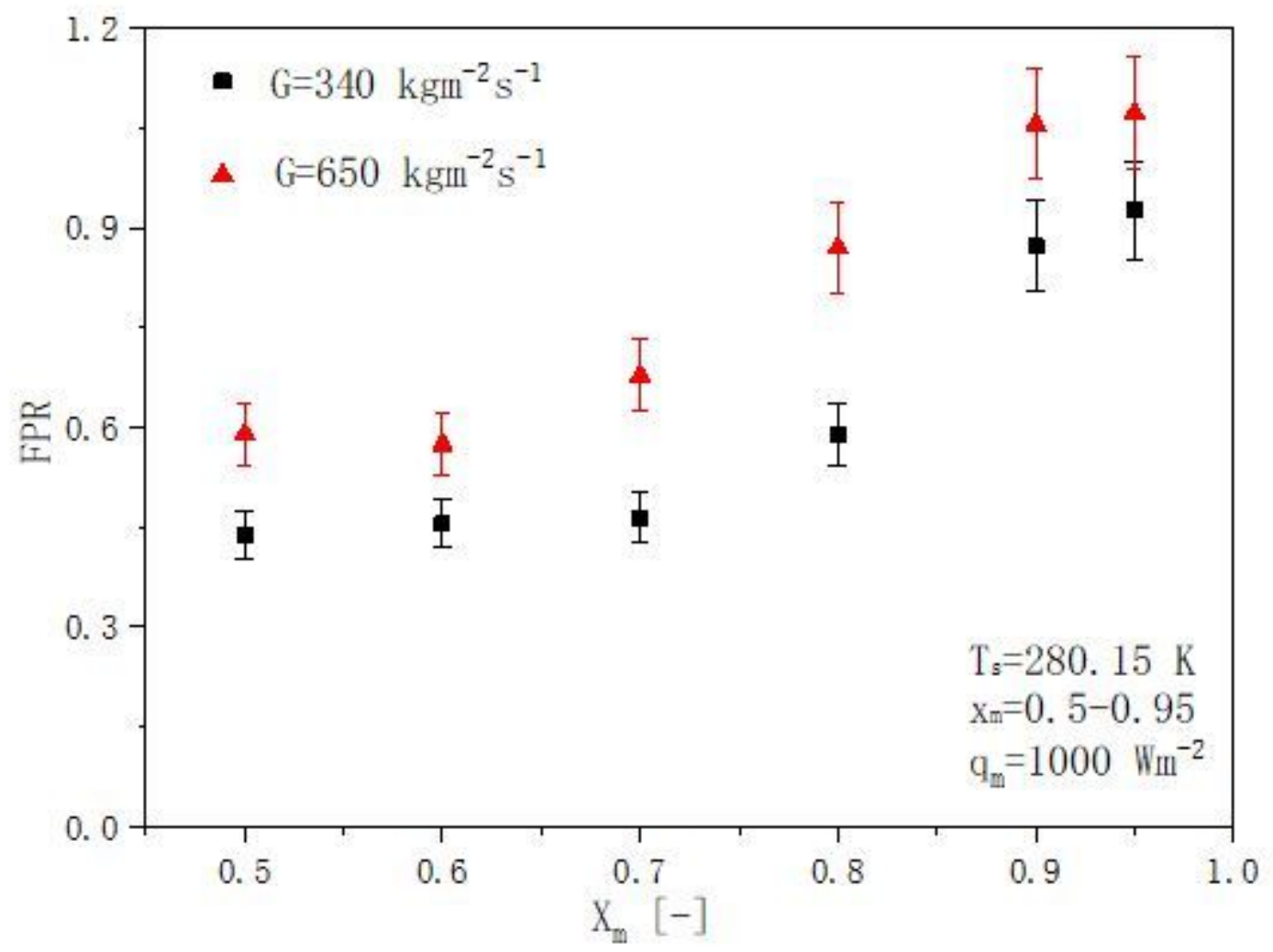


Figure 15

The FPR of both evaporators

\section{Supplementary Files}

This is a list of supplementary files associated with this preprint. Click to download.

- tables.docx 